\title{
Eyes Bigger Than the Tummy: A Comparative Evaluation of Cooking and Drinking Preferences vs. Healthy Cooking and Drinking Knowledge in Childhood
}

\author{
Maria do Rosário Dias (Corresponding author) \\ Egas Moniz - Multidisciplinary Research Centre in Health Psychology, Caparica, Portugal \\ E-mail: mariadorosario.dias@gmail.com \\ Alexandra Freches Duque \\ Egas Moniz - Multidisciplinary Research Centre in Health Psychology, Caparica, Portugal
}

Received: 13-02- 2016

Accepted: 16-04-2016

Published: 30-04-2016

doi:10.7575/aiac.ijels.v.4n.2p.13

URL: http://dx.doi.org/10.7575/aiac.ijels.v.4n.2p.13

\begin{abstract}
Childhood overweight and obesity have been increasing over recent years and, more than ever, we are being called to act, whether as clinicians, parents or educators. The aim of this empirical research is to assess children's cognitive and emotionally internalized mental representation of a Preferred and Healthy Meal, using drawing as methodological instrument. This is a cross-sectional, exploratory and descriptive study using a qualitative methodology - content analysis. In the present research, conducted in two moments, with 1013 children (aged 4-10 years), from Lisbon metropolitan area, we've asked children to draw a Preferred Meal and a Healthy Meal, trying to evaluate the child's implicit knowledge and habits of drink intake and food cooking methods. 2026 drawings were collected: 1013 representing a Preferred Meal and 1013 a Healthy one. Drawings were evaluated using a content analysis instrument specifically developed for this study, using ATLAS.ti 6. For purposes of obtaining a descriptive analysis, data were treated using the Statistical Package for the Social Sciences (SPSS) 19.0 for Windows. The obtained results on Cooking Methods (sub-categories Meat, Fish and Potatoes) reveal that children, regarding the Preferred Meal, selected both healthier and unhealthier cooking methods like Fried (Meat and Potatoes), Stewed and Grilled (Meat). Representations of healthy cooking methods, on the other hand, show conspicuous disparities by age-group as children aged 4 and 5 years take frying as a healthy meat cooking method, whereas children aged 6 years are virtually unanimous in choosing grilling as the best representation of healthy meat cooking method. As to Potato and Fish healthy cooking methods, most children elect boiling. Regarding the beverages that children included in their Preferred Meals, we found some discrepancies with selection of fresh juices in the age-groups $4 \mathrm{YG}$ and $5 \mathrm{YG}$ with clear contrast with the dominance of soft drinks (carbonated beverages sweetened with sugar) in the older groups. Regarding healthy drink choices, soft drinks decrease drastically, being consensually replaced by Water in all age groups or by Natural / Fresh Juices in the younger age groups, despite an undeniable presence of soft drinks, disguised of "natural". The results obtained in the study points out that preferred cooking methods and drinks are internalized during childhood and are connected to early experiences with food and to pathogenic (family and society) nutritional patterns. They also testify to the children's ability to learn to select healthy cooking methods, despite being an abstract cognitive construct, at a very early age. Despite that knowledge, when it comes to drinks, this study evidences that children's reveal some erroneous representations influenced by exposure to media, namely related to advertising soft drinks bearing a 'healthy food' label. These are the stronger arguments to support the need for developing health education ludic-pedagogic instruments for children.
\end{abstract}

Keywords: Drinking behaviours; Cooking Methods; Childhood Overweight; Child Obesity; Health Education

\section{Introduction}

Obesity is the epidemic of the XXI century, and children are not safe from this disease. The literature review reveals that eating behaviours acquired at an early age contribute to the quality of future eating habits, so this is the basic premise of our work. In fact, studies reveal that eating habits developed during the first years of life determine the quality of eating habits in later years (Andrade, 2004; Birch \& Fisher, 1998; Cavalcanti, Dias \& Costa, 2005; Garcia \& Canesqui, 2005). Children intake preferences are, notwithstanding, major determinants of eating/drinking patterns, and evidence reveals that preferences are linked to dietary patterns, which in turn influence the risk of overweight, obesity and chronic disease (Birch, 1989).

It has been established that intake habits and practices are built upon sociocultural determinants (Rossi \& Silveira, 2002; Serra \& Santos, 2003), and that food and drink selection is part of a somewhat entangled behavioural system. 
When children are concerned, it is the parents/family cocoon that determines the continuing interaction with these items, intake preferences and primary intake habits (Reichembach, 2004; Savage, Fisher \& Birch, 2007). That said, peer influence can be more powerful than parents' influence, and it has proved to be particularly effective in pre-schoolers (Basedevant, Boute \& Borys, 1999; Birch, 1980; Birch \& Marlin, 1982; Birch, 1989; Birch, 1998).

One should also add to these that the reality we live in entices and induces, through various channels, the adoption of unhealthy behaviours (Cypress, 2004), accommodating an 'obesogenic environment' (Dias, Julião, Reis, Camolas \& Duque, 2006; Dias, Julião, Reis \& Duque, 2008; Dias, Reis, Julião \& Duque, 2007) - a facilitator of ample access to high energetic density foods/drinks and, therefore, a promoter of child obesity and excessive weight gain (Fisberg, 2005; WHO, 2003). Shaping or re-shaping children's intake behaviour education requires from health professionals, parents and educators that they possess an in-depth knowledge of the child's affective-emotional development and corresponding implications at the level of the underlying cognitive processes involved in unmasking the obesogenic reality' (Dias, Julião, Reis, Camolas \& Duque, 2006; Dias, Julião, Reis \& Duque, 2008; Dias, Reis, Julião \& Duque, 2007) experienced by the child, which will inevitable determine healthy or unhealthy intake choices and have repercussions in their comprehension of messages on nutrition education regarding concepts and processes on food, drinks and eating choices and habits (Michaela \& Contento, 1986; Westenhoefer, 2002). One must not forget, however, that nutrition education strategies, especially in childhood, are clearly limited by the child's cognitive developmental stage (Westenhoefer, 2002).

Departing from the hypothesis that a content analysis of drawings made by pre-school and school-aged children will reveal clear differences concerning already acquired drinks' and cooking methods' preferences, we set ourselves, with the current empirical study, to analyse children's symbolic representations associated to nutritional behaviours, so as to identify 'objective illustration profiles' corresponding to Preferred Cooking Methods and Drinks and Healthy Cooking Methods and Drinks, which will allow for a further identification of future implications concerning the prevention of child excess weight and obesity.

Our empirical research is aimed at assessing children's cognitively and emotionally internalised mental representation on what constitutes a Preferred Meal vis-à-vis a Healthy Meal, using the resource drawing as methodological instrument.

\section{Materials and Methods}

We have designed a cross-sectional, exploratory and descriptive study using a qualitative methodology - content analysis. In the present research, conducted in two moments, with 1013 children (aged 4-10 years), from Lisbon metropolitan area, we've asked children to draw a Preferred Meal and a Healthy Meal, trying to evaluate the child's implicit knowledge and habits of drink intake and food cooking methods. A black-and-white pictogram representing the typical containers and utensils used during a meal - one plate, one fork, one knife and one glass - was presented, on which the child was to draw their meals, specifically, meals that represent a family dinner.

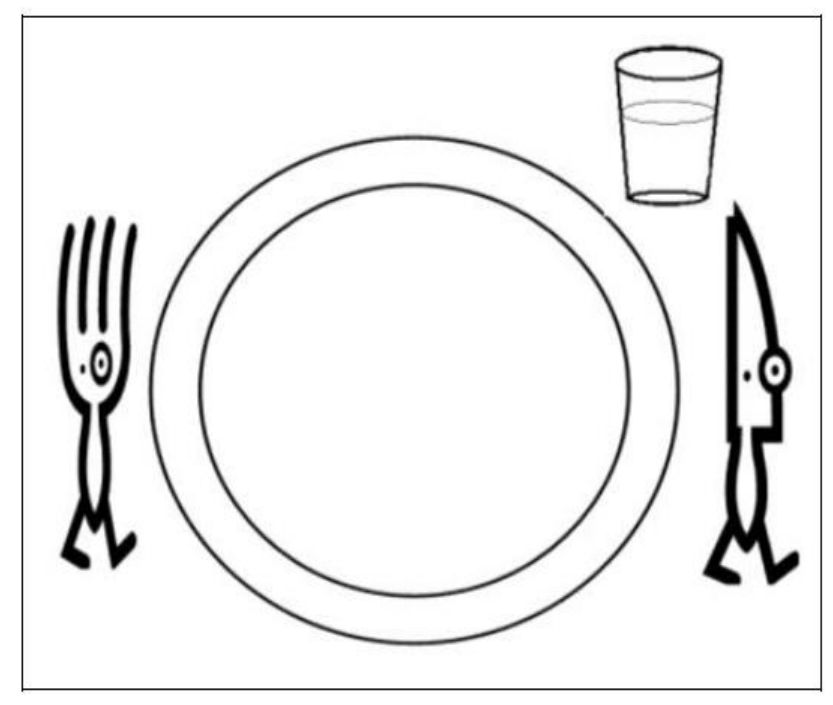

Picture 1. Pictogram representing the various utensils used during a meal, simulating a 'set table' (plate, fork, knife and glass) 


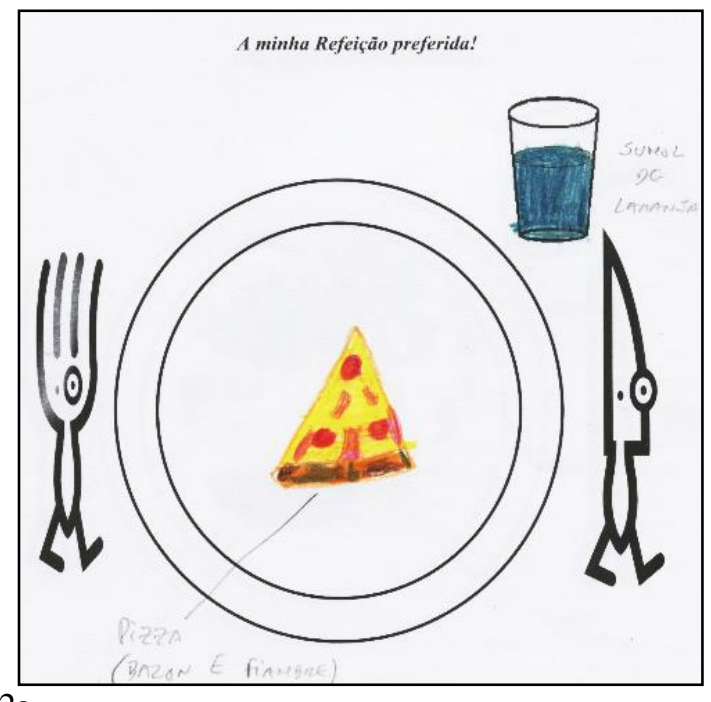

$2 \mathrm{a}$

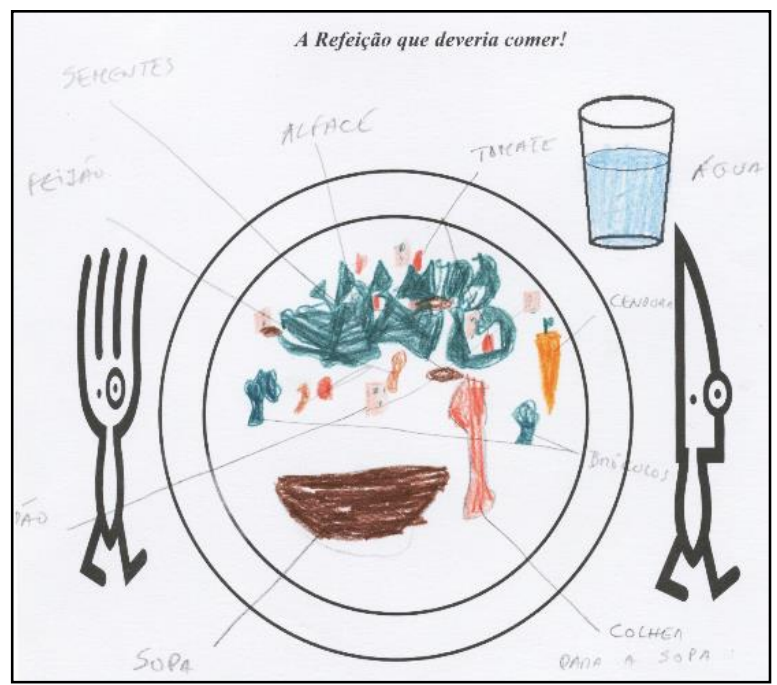

$2 b$

Pictures $2 \mathrm{a}$ and $2 \mathrm{~b}$. Examples of pictograms illustrating a Preferred Meal (a) and a Healthy Meal (b). Captions read: 'This is my favourite meal!' (a) [Pasta, mayonnaise, meat + orange juice] and 'This is the meal I should have!' (b) [Roasted meat, baked fish, bread, pear + orange juice]. Food items are shown as drawn by the child. Upon completing the drawing, each child would orally indicate to the researcher which food items s/he had represented, and the researcher would accordingly write down the verbal information provided.

In this study, 2026 drawings were collected: 1013 representing a Preferred Meal and 1013 a Healthy one. To analyse the content of the drawings, we used an instrument-grid of analytical categories, specifically designed for this study, using ATLAS.ti 6. This grid is composed of five (5) basic categories and sixteen (16) additional analytical subcategories.

Table 1. Instrument-grid of analytical categories, composed of five (5) basic categories and sixteen (16) additional analytical subcategories.

\begin{tabular}{ll}
\hline \multicolumn{1}{c}{ Category } & \multicolumn{1}{c}{ Subcategories } \\
\hline \multirow{3}{*}{ 1. Carbohydrates } & Cereal grains and respective derivatives and Tubers \\
& Vegetables \\
& Sweets and deserts \\
& Cooking methods \\
\hline & Meats \\
2: Proteins & fishes and eggs \\
& Milk and Dairy products \\
& Cooking methods \\
\hline & Vegetables \\
3: Dietary fibre, Vitamins and Minerals & Soups \\
& Fruits \\
\hline 4: Fats & Sauces \\
& Fast-food \\
\hline & Water \\
5: Drinks & Soft drinks \\
& Fresh fruit/vegetable juices \\
& Wine \\
\hline
\end{tabular}

Note: To these, a further eighty nine (89) sub-subcategories are to be added, so as to represent the myriad of food and drink items drawn by the children. 
The theoretical and practical foundation for instrument was based on the conceptualisation of the 'Roda dos Alimentos' ['Food Wheel'], created in 1977 for the Food Education Campaign 'Saber comer é saber viver' ['Knowing how to eat is knowing how to live'], and on the expert opinions of a nutritionist and a medical doctor. The object behind the development of the 'Food Wheel' was converting complex nutritional information into simple concepts, easy to understand and easy to follow by the general population. The circle group's food items according to their nutritional properties, featuring a total of five large clusters, each occupying a differentiated area of the circle, thus pictorially indicating the relative weight with which each group should contribute so as to obtain a daily balanced diet (FCNAUP \& Instituto do Consumidor, 2004; Peres, 1994). Since its introduction, changes in the Portuguese population's dietary patterns and incoming new information, led to a necessary updating of the 'Food Wheel'. Its original format was maintained, for it preserves the notion of not ranking food items in a hierarchy and it associates the daily dietary intake to the object plate - sign of a food culture that happens around a table. When restructuring the 'Food Wheel', learning objectives concerning nutrition were not the only aspect considered; the promotion of cultural and social values pertaining to the Portuguese society was also taken into account. The 'New Food Wheel' displays seven food groups with varying dimensions, once more indicating the proportion allotted to each group in a daily balance regime. Given that water is a constituent part of almost every food item, and indispensable to life, it is now given representation in the core of the wheel (DGS, 2005; FCNAUP \& Instituto do Consumidor, 2009; Franchini, Rodrigues, Graça \& Almeida, 2004).

The information gathered through the drawings was collected in two distinct, albeit consecutive, moments (M1 and M2). The child was first asked to draw their Preferred Meal (M1) on the pictogram supplied, and, upon completing that first drawing, asked to draw a second one, this time an illustration of a Healthy Meal (M2). In both drawings, the instruction given specified that the meal should represent what the children would eat on a typical family dinner. Once the drawings were finished, all their elements were identified by the researcher(s) according to the children's descriptions, in order to minimize erroneous interpretations.

For purposes of obtaining a descriptive analysis, data were treated using the Statistical Package for the Social Sciences (SPSS) 19.0 for Windows.

Phase I of the current research involved a total of 377 pre-school children, aged 4-6 years, of both sexes, distributed into three age-groups $(4 \mathrm{YG}=108 ; 5 \mathrm{YG}=128 ; 6 \mathrm{YGa}=137)$. At the time the data were collected, participant children attended kindergarten/pre-schools located on the Metropolitan Area of Lisbon and were members of medium-low income families. 746 valid drawings were collected (373 representing a Preferred Meal and 373 representing a Healthy Meal).

Phase II of the current research involved a total of 640 school-aged children (6-10 years) of both sexes were distributed into three age-groups $(6 \mathrm{YGb}=85 ; 7 \mathrm{YG}=140 ; 8 \mathrm{YG}=170 ; 9 \mathrm{YG}=150 ; 10 \mathrm{YG}=95)$ and were given the same instruction (M1 and M2). At the time the data were collected, participant children attended primary schools located on the Metropolitan Area of Lisbon and were members of medium-low income families. 1280 valid drawings were collected (640 representing a Preferred Meal and 640 representing a Healthy Meal).

\section{Results}

The obtained results on Cooking Methods (sub-categories Meat, Fish and Potatoes) allow us to identify how cooking methods relate to meal type (preferred versus healthy) by age-group which, in turn, allow us to draw a few inferences on health-promoting versus pathogenic dietary profiles.

Looking at the results for Meat in the Preferred Meal, Fried (4YG: 80\%; 6YGa: 72\%) and Stewed (5YG: 43\%) meat are the clearly preferred cooking methods in the younger group. In the school-aged group the Preferred Meal representations children's preferences are more diversified: Fried (6YGb: 12\%; 8YG: 11\%), Grilled (7YG: 9\%; 9YG: $11 \%$ ) or Stewed (10YG: 10\%). Representations of healthy cooking methods, on the other hand, show conspicuous disparities by age-group: children aged 4 and 5 years take frying as a healthy meat cooking method (4YG: 57\%; 5YG: $50 \%$ ), whereas children aged 6 years are virtually unanimous in choosing grilling as the best representation of healthy meat cooking method. Disparity notwithstanding, attention should be called to the decrease in the percentage of representations of fried meat in the 4YG (Preferred Meal: 80\%; Healthy Meal: 57\%), as well as their increase in the 5YG (Preferred Meal: 20\%; Healthy Meal: 50\%). Within Healthy Meal representations of the older group, a like disparity is also observed: in 6-year olds' drawings, meat was represented as Fried meat (6YGb: 7\%); 8-year olds represented it as Roasted meat (8YG: 3\%); children aged 9 years drew pictures of Boiled meat (9YG: 3\%); and children aged 7 and 10 years indicated Grilling as the healthiest method for cooking meat (7YG: 5\%; 10YG: 3\%).

It should be pointed out that, despite an absence of contrast between preferred and healthy in the 6YGb, supported by the disparities in the younger group, an age-group where notions of healthy / preferred cooking methods can be said to be overall concurrent, instances of Fried meat in Healthy Meal pictures decrease to a vanishing point as we move upwards on the age-groups (6YGb: 7\%; 7YG: 2\%; 8YG: 2\%; 9YG: 0\%; 10YG: 0\%). 
Table 2. Meat cooking methods: Preferred Meal vs. Healthy Meal

\begin{tabular}{rcccccccccc}
\hline & \multicolumn{3}{c}{ Preferred Meal } & \multicolumn{3}{c}{ Healthy Meal } \\
\hline & $\begin{array}{c}\text { Fried } \\
\text { Meat }\end{array}$ & $\begin{array}{c}\text { Grilled } \\
\text { Meat }\end{array}$ & $\begin{array}{c}\text { Roasted } \\
\text { Meat }\end{array}$ & $\begin{array}{c}\text { Boiled } \\
\text { Meat }\end{array}$ & $\begin{array}{c}\text { Stewed } \\
\text { Meat }\end{array}$ & $\begin{array}{c}\text { Fried } \\
\text { Meat }\end{array}$ & $\begin{array}{c}\text { Grilled } \\
\text { Meat }\end{array}$ & $\begin{array}{c}\text { Roasted } \\
\text { Meat }\end{array}$ & $\begin{array}{c}\text { Boiled } \\
\text { Meat }\end{array}$ & $\begin{array}{c}\text { Stewed } \\
\text { Meat }\end{array}$ \\
\hline 4 & $80 \%$ & $0 \%$ & $10 \%$ & $10 \%$ & $10 \%$ & $57 \%$ & $2 \%$ & $10 \%$ & $0 \%$ & $22 \%$ \\
5 & $20 \%$ & $0 \%$ & $23 \%$ & $2 \%$ & $43 \%$ & $50 \%$ & $2 \%$ & $50 \%$ & $0 \%$ & $2 \%$ \\
$6 a$ & $72 \%$ & $0 \%$ & $18 \%$ & $18 \%$ & $2 \%$ & $2 \%$ & $96 \%$ & $2 \%$ & $0 \%$ & $2 \%$ \\
$6 b$ & $12 \%$ & $4 \%$ & $6 \%$ & $1 \%$ & $7 \%$ & $7 \%$ & $2 \%$ & $2 \%$ & $2 \%$ & $1 \%$ \\
7 & $6 \%$ & $9 \%$ & $6 \%$ & $2 \%$ & $4 \%$ & $2 \%$ & $5 \%$ & $3 \%$ & $3 \%$ & $1 \%$ \\
8 & $11 \%$ & $9 \%$ & $5 \%$ & $2 \%$ & $8 \%$ & $2 \%$ & $2 \%$ & $3 \%$ & $2 \%$ & $1 \%$ \\
9 & $10 \%$ & $11 \%$ & $7 \%$ & $2 \%$ & $8 \%$ & $0 \%$ & $2 \%$ & $1 \%$ & $3 \%$ & $1 \%$ \\
10 & $6 \%$ & $6 \%$ & $7 \%$ & $1 \%$ & $10 \%$ & $0 \%$ & $3 \%$ & $0 \%$ & $1 \%$ & $1 \%$ \\
\hline
\end{tabular}

When deciding between Fish Cooking Methods in the representation of Healthy Meal, there is a larger convergence among age-groups, where boiling is, for every age-group, the more frequently represented cooking method (4YG: 67\%; 5YG: $71 \%$; 6YG: $47 \%$ ).

In the older group, the Healthy Meal's choices as to Fish cooking methods also show an inter-group convergence, where boiling features as the more often chosen health-promoting method for cooking fish (6YGb: $21 \%$; $7 \mathrm{YG}$ : $31 \%$; 8YG: $32 \%$; 9 YG: $35 \%$; 10YG: $45 \%$ ).

Table 3. Fish cooking methods: Healthy Meal

\begin{tabular}{ccccc}
\hline & Fried Fish & Grilled Fish & Roasted Fish & $\begin{array}{l}\text { Boiled } \\
\text { Fish }\end{array}$ \\
\hline 4 & $30 \%$ & $2 \%$ & $2 \%$ & $67 \%$ \\
5 & $20 \%$ & $20 \%$ & $2 \%$ & $71 \%$ \\
$6 a$ & $10 \%$ & $30 \%$ & $10 \%$ & $47 \%$ \\
\hline $6 b$ & $7 \%$ & $2 \%$ & $0 \%$ & $21 \%$ \\
7 & $5 \%$ & $6 \%$ & $3 \%$ & $31 \%$ \\
8 & $4 \%$ & $6 \%$ & $4 \%$ & $32 \%$ \\
9 & $5 \%$ & $11 \%$ & $5 \%$ & $35 \%$ \\
10 & $4 \%$ & $4 \%$ & $4 \%$ & $45 \%$ \\
\hline
\end{tabular}

Note: Because there were no references to fish in the Preferred Meal, we can only present fish cooking methods regarding the Healthy Meal

As to Potato Cooking methods, it appears that children in all age-groups, form the younger group, have a preference for having their potatoes as Fries (4YG: 81\%; 5YG: 78\%; 6YGa: 81\%). When looking at Healthy Meal profiles, however, most children elect boiling as a healthy potato cooking method (4YG: 37\%; 5YG: 54\%; 6YGa: 77\%). It is worth pointing out that, in the 4YG's representations of Healthy Meal, while most children still indicate frying as a healthy cooking method where potatoes are concerned, despite that percentage being significantly lower than the one found in their Preferred Meal pictorial representations (Preferred Meal: 81\%; Healthy Meal: 46\%).

In the older group, the preferred method for cooking Potatoes is, consensually, the frying method, (6YGb: 35\%; $7 \mathrm{YG:}$ 47\%; 8YG: 44\%; 9YG: 44\%; 10YG: 45\%), but also consensual is the notion that the preferred choice is not the healthiest; frying is outstandingly replaced by boiling, which is clearly taken to be a healthier potato cooking method (6YGb: 17\%; 7YG: 30\%; 8YG: 39\%; 9YG: 49\%; 10YG: 53\%). 
Table 4. Potatoes cooking methods: Preferred Meal vs. Healthy Meal

\begin{tabular}{rrrrrrrrr}
\hline \multicolumn{7}{c}{ Preferred Meal } & \multicolumn{5}{c}{ Healthy Meal } \\
\hline & $\begin{array}{c}\text { Fried } \\
\text { Potatoes }\end{array}$ & $\begin{array}{c}\text { Boiled } \\
\text { Potatoes }\end{array}$ & $\begin{array}{c}\text { Roasted } \\
\text { Potatoes }\end{array}$ & $\begin{array}{c}\text { Mashed } \\
\text { Potatoes }\end{array}$ & $\begin{array}{c}\text { Fried } \\
\text { Potatoes }\end{array}$ & $\begin{array}{c}\text { Boiled } \\
\text { Potatoes }\end{array}$ & $\begin{array}{c}\text { Roasted } \\
\text { Potatoes }\end{array}$ & $\begin{array}{c}\text { Mashed } \\
\text { Potatoes }\end{array}$ \\
\hline 4 & $81 \%$ & $2 \%$ & $0 \%$ & $0 \%$ & $46 \%$ & $37 \%$ & $0 \%$ & $18 \%$ \\
5 & $78 \%$ & $10 \%$ & $0 \%$ & $2 \%$ & $20 \%$ & $54 \%$ & $0 \%$ & $18 \%$ \\
$6 a$ & $81 \%$ & $8 \%$ & $0 \%$ & $4 \%$ & $20 \%$ & $77 \%$ & $0 \%$ & $2 \%$ \\
$6 b$ & $35 \%$ & $6 \%$ & $0 \%$ & $0 \%$ & $2 \%$ & $17 \%$ & $0 \%$ & $0 \%$ \\
7 & $47 \%$ & $6 \%$ & $1 \%$ & $1 \%$ & $2 \%$ & $30 \%$ & $0 \%$ & $1 \%$ \\
8 & $44 \%$ & $5 \%$ & $0 \%$ & $2 \%$ & $5 \%$ & $39 \%$ & $1 \%$ & $1 \%$ \\
10 & $44 \%$ & $9 \%$ & $0 \%$ & $3 \%$ & $1 \%$ & $49 \%$ & $1 \%$ & $1 \%$ \\
\hline
\end{tabular}

Looking at Healthy Meals profiles obtained, the meal that every age-group seems to have single out is boiled Fish with boiled Potatoes. That shows that children in all age-groups have quite clearly assimilated the notion of 'healthy meal' is further supported in the low incidence of representations of unhealthy cooking methods in their Healthy Meal drawings. Despite 'cooking method' is an abstract notion for children in these ages, our results point to an early acquisition of these concepts.

Considering now the beverages that children included in their Preferred Meals pictorial representations, our results show a predominance of fresh juices in the age-groups $4 \mathrm{YG}(42 \%)$ and $5 \mathrm{YG}(51 \%)$, offering a clear contrast with the dominance of soft drinks (carbonated beverages sweetened with sugar) in the 6YGa (76\%). This finding might be explained if we consider that the acquisition of food repertoire is likely to be influenced by food exposure. This is supported by the older group findings, where children in all age-groups state a marked preference for Soft Drinks (6YGb: 70\%; 7YG: 66\%; 8YG: 64\%; 9YG: 65\%; 10YG: 74\%).

In contrast, when the question is no longer one of preference, rather of stating what constitutes a healthy drink choice, soft drinks decrease drastically, being consensually replaced by Water in all age groups (4YG: 34\%; 5YG: 40\%; 6YGa: 42\%; 6YGb: 70\%; 7YG: 79\%; 8YG: 71\%; 9YG: 73\%; 10YG: 67\%). A tendency that also holds true for Natural / Fresh Juices in the younger age groups (4YG: $36 \%$; $5 \mathrm{YG}: 36 \%$ ). In the $6 \mathrm{YGa}$, however, the percentage of representations of Soft Drinks is still high (46\%), although lower than the one found in Preferred Meal drawings (76\%).

Table 5. Drinks: Preferred Meal vs. Healthy Meal

\begin{tabular}{ccccccc}
\hline \multicolumn{3}{c}{ Preferred Meal } & \multicolumn{3}{c}{ Healthy Meal } \\
\hline & Water & $\begin{array}{c}\text { Soft } \\
\text { drinks }\end{array}$ & Natural Juice & Water & $\begin{array}{c}\text { Soft } \\
\text { drinks }\end{array}$ & Natural Juice \\
\hline 4 & $20 \%$ & $30 \%$ & $42 \%$ & $34 \%$ & $20 \%$ & $36 \%$ \\
5 & $19 \%$ & $22 \%$ & $51 \%$ & $40 \%$ & $18 \%$ & $36 \%$ \\
$6 a$ & $16 \%$ & $76 \%$ & $16 \%$ & $42 \%$ & $46 \%$ & $6 \%$ \\
$6 b$ & $15 \%$ & $70 \%$ & $14 \%$ & $70 \%$ & $12 \%$ & $14 \%$ \\
7 & $16 \%$ & $66 \%$ & $17 \%$ & $79 \%$ & $6 \%$ & $13 \%$ \\
8 & $14 \%$ & $64 \%$ & $21 \%$ & $71 \%$ & $9 \%$ & $14 \%$ \\
9 & $12 \%$ & $65 \%$ & $23 \%$ & $73 \%$ & $7 \%$ & $17 \%$ \\
10 & $8 \%$ & $74 \%$ & $17 \%$ & $67 \%$ & $11 \%$ & $18 \%$ \\
\hline
\end{tabular}

\section{Discussion}

The internalization of healthy eating behaviours acquired in early childhood will condition one's eating behaviours in subsequent development stages (Andrade, 2004; Birch \& Fisher, 1998; Cavalcanti, Dias \& Costa, 2005; Garcia \& Canesqui, 2005) and a negative impact on adult disease and mortality rates (Story \& French, 2004; von Normann, 2009). As such, in order to foster a child's healthy development, it is necessary to promote, teach and cultivate a balanced and attractive nutritional regime. Children should learn how to eat, just as they learn how to speak and read, for one's eating behaviour is a relational, social and cultural act (Dias, Julião, Reis \& Duque, 2008; Dias, Reis, Julião \& Duque, 2007). 
The fact that the concept of 'cooking method' is, for children as young as those who took part in this study, an abstract cognitive construct, did not prevent that, in both groups/phases, when contrasting Healthy with Preferred Meal, children revealed their acquired knowledge, mostly representing Fish and Potatoes as boiled, in the Healthy Meal and, when present, meat would only be represented as grilled. In the same line of results, Water is the beverage presented as the archetypical healthy drink, increasing its representation frequency with age, testifying to the acquisition and internalization of cognitive information on the importance of drinking it. These findings are a good indicator regarding the early acquisition of healthy nutrition knowledge, in line with other papers that state that research show that from 6 years onwards, children start to discriminate and develop understanding of which food types that are good for them (Strachan \& Pavie-Latour, 2008). However, these results don't talk about children's choices since Preferred Meal revealed quite unhealthy choices, some that so young children probably shouldn't even know its existence, because of the life time impact of such products. These are, of course concerning results since children food preferences are major determinants of food eating patterns or of food consumption standards, and evidence has revealed that preferences are linked to dietary patterns, which in turn influence the risk of overweight, obesity and chronic disease (Birch, 1989). This is exemplified by the massive presence of Soft Drinks as the preferred beverage in the population aged 6-10 years, contrasting with the preferences expressed by children aged 4 and 5 years, which presented Fresh Juices as their drink of choice. These results may find explanation on the fact that children's 'nutritional-cognitive repertoire' is influenced by exposure to media with massive television advertising campaigns in children prime time, as well as peer pressure, and by the excessive mercantilist availability of food products considered unhealthy. Many of those products are currently advertised and put on the market bearing a 'healthy food' label, and even as rightful substitutes for fresh fruit, thus acquiring (mainly among school-aged children) an erroneous social representation - a notion that obviously calls for immediate demystification on the part of parents and educators. Research findings indicate that food advertising increases children's awareness, interest and purchase intention (Harris, Pomeranz, Lobstein \& Brownell, 2009) and have a causal and direct effect on children's food preferences, knowledge and behaviour (Livingstone, 2005). In fact, such erroneous representation should be filtered and demystified by parents and educators when assuming their role as health educators in their relation with the children. Furthermore, we need also to consider peer influence, many times more powerful than parents' influence that has been proved to be more effective in preschoolers (Basedevant, Boute \& Borys, 1999; Birch, 1980; Birch \& Marlin, 1982; Birch, 1989; Birch, 1998).

However, not all parents (and educators) have this knowledge, believing that giving children the so-called "healthy" soft drinks is a healthy behaviour, or at least a 'minor nutritional sin', contributing to an overall healthy pattern of their children, deviating them form the "bad" soft drinks consumption. Therefore, attention should be focused on the psychosocial determinants, to identify the «toxic environment» (Ebbling, Pawlak \& Ludwig, 2002) that influences the precocity of the formation of children's eating choices. A consistent policy for obesity and excess weight prevention must involve information and education campaigns directed at parents, educators and schools as a whole, legal and fiscal measures, 'refreshment training programmes' for health professionals, as well as support measures to both the production and the commercialization of healthy food. These measures should focus on the children as targetpopulation, specifically, on the children's awareness that they control their own well-being through food choices, motivating them to take active part in the food decision process. Primary prevention initiatives seem to be the most efficient ones, particularly if initiated prior to entering school and maintained during childhood and adolescence, thus providing an education on nutrition throughout these stages of development.

But we must not forget that nutritional education strategies, especially in childhood, are clearly limited by children's cognitive developmental stage (Westenhoefer, 2002). So, an understanding of how (and when) children's food preferences are acquired and internalized is essential for the development of strategies that may contribute, in the future, to improve health education programs for children (Dias, Reis, Julião \& Duque, 2007), we believe this is our main contribution to these field. Understanding food preferences of children as young as 4 years old, and watching them be transformed over the years by peer and media pressure, might shed some light over the drawn strategies to prevent child and adult overweight and unhealthy eating habits. Atik and Ozdamar Ertekin (2011) refer some dimensions of food that can be appealing to children, like sensory, fun and play appeals, taste and appeal of the forbidden as well as aesthetic appeals. Therefore, all socializing agents such as parents, school, teachers and marketers could work on the aesthetic and 'fun and play' aspects of 'healthy food' to make it more appealing to children and thus help to combat obesity.

When it comes to implementing dietary health programs, based on the drawing from the younger group, we have developed an educational textbook on healthy eating, in the form of a children's literature book, aimed at children in their early development stages (aged 4-6 years). The book was intentionally given the title 'Now Go and Break a Plate', and the object of its narrative, which main character is a plate, is to convey appropriate nutritional advice through a playful and pedagogic instrument. The book is intended to be read/explored by the child, on their own, in their 'secret playing', but it is also intended as a gateway into a "shared imaginary", whenever its reading is 'played' with an adult - a parent or an educator. By "breaking a plate", the authors, assuming a multidisciplinary approach, engaged in the adventure of sharing a daily experience with the child. Using illustrations and words, seven healthy meals are presented, thus helping the child to overcome 'minor nutritional sins and temptations'. The narrative presented is anchored in five golden rules for the promotion of healthy eating habits and liquid's ingestion. It also provides basic notions on distribution and composition of meals, as well as on cooking methods that result in less caloric meals. 


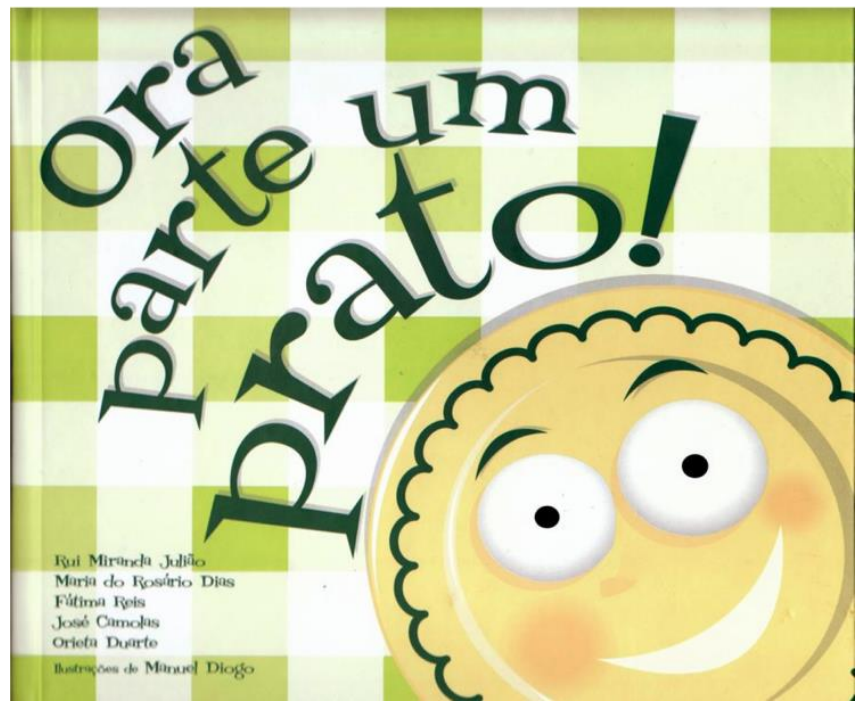

Picture 3. "Ora Parte um Parto” ('Now Go and Break a Plate') Book Cover

A second children's literature book, also converted in to an educational textbook on healthy eating, is being outlined and constructed at the moment by the research team, sustained by the results of the older group. The book's narrative will be attempted as an answer to the specific needs of school-aged, 6 to 10 year old, children - an age period also known as 'age of reason', where logic-deductive reasoning prevails. It is also a period where children, in their internal experiences, are driven by the need to understand what it is that is entailed by 'autonomous socialization' in the context of their daily experience, and in the social roles assumed with their relational objects - parents, peers and educators. The playful and learning challenge/adventure the readers of the book will face by having a 'supermarket cart' as the main character in the story is intended to promote children's autonomy in selecting and acquiring food items. A further object is that of promoting healthy cooking methods, using, as a learning aid, the calories and nutritional values displayed in food items' labels.

This paper pretends to bring some new information about eating habits development in childhood. We've chose a qualitative methodology, despite its limitations, because these design is well accepted by children and offers an insight on their unconscious conceptions and knowledge on the subject, so it has the power to bring new data. One of the most common limitations of qualitative analysis is the number of subjects, so, we gathered a strong sample of children, despite the differences between the groups that might also be seen as a limitation of this study. Another study limitation includes the difficulty of replication, because of the expensiveness and time-consuming nature of the collection and analysis of the research information. Moreover, we cannot generalize our results to all children independently of their demographic variables, and we cannot make quantitative predictions.

Despite all this, when trying to change children choices, we should all remember that learning while playing is the most effective way of imprinting long-lasting knowledge and behaviour patterns.

\section{References}

Andrade, G. (2004). A Promoção de Comportamentos Alimentares Saudáveis na Criança: Uma Abordagem Desenvolvimentista. In I. Leal, I. Cabral \& J. Ribeiro (Eds.), Actas do $4^{o}$ Congresso Nacional de Psicologia da Saúde (pp. 13-18). Lisboa: ISPA.

Atik, D. and Ozdamar Ertekin, Z. (2013). Children's perception of food and healthy eating: dynamics behind their food preferences. International Journal of Consumer Studies, 37, 59-65. doi: 10.1111/j.1470-6431.2011.01049.x

Basedevant A., Boute, D. \& Borys, J. (1999). Who Should Be Educated? Education Strategies: Could Children Educate Their Parents? Journal of Obesity and related Metabolic Disorders, 23, 10-13.

Birch, L. (1980). Effects of Peer Models' Food Choices and Eating Behaviours on Preschoolers' Food Preferences. Child Development, 51, 489-496.

Birch, L. (1989). Developmental Aspects of Eating. In R. Shepherd (Ed.), Handbook of the Psychophysiology of Human Eating (pp. 179-203). Chichester: Wiley.

Birch, L. (1998). Psychological Influences on Childhood Diet. Journal of Nutrition, 128, 407-410.

Birch, L. \& Fisher, J. (1998). Development of Eating Behaviours among Children and Adolescents. Pediatrics, 101, 539-549. 
Birch, L. \& Marlin, D. (1982). I Don't Like It; I Never Tried It. Effects of Exposure to Food on Two-year-old Children's Food Preference. Appetite, 4, 353-360.

Cavalcanti, A., Dias, M., \& Costa, M. (2005). Psicologia e Nutrição: Predizendo a Intenção Comportamental de Aderir a Dietas de Redução de Peso Entre Obesos de Baixa Renda. Estudos de Psicologia, 10(1), 121-29.

Cypress, M. (2004). Looking Upstream. Diabetes Spectrum, 17, 249-253.

DGS. (2005). A Nova Roda dos Alimentos. Retrieved on August 24, 2006 from http://www.portaldasaude/portal/conteudos/enciclopedia+da+saude/alimentacao/DGS+ANA.htm

Dias, M.R., Julião, R.M., Reis, M.F. \& Duque, A. F. (2008). “Choose The Meal!”: A Health Education Project on Childhood Food Preferences. EACH 2008 - International Conference in Healthcare - Programme and Abstracts, P2.2.04.

Dias, M.R., Julião, R.M., Reis, M.F., Camolas, J.L. \& Duque, A. F. (2006). Eyes Bigger Than The Tummy: Preventing Childhood Overweight. EACH 2006 - International Conference in Healthcare - Programme and Abstracts, P31.04.

Dias, M.R., Reis, M.F., Julião, R.M. \& Duque, A. F. (2007). The Eyes are The Window of The Tummy: Preventing Childhood Overweight (Ref.: 125). Health Psychology Review - Abstracts Book, 1 (Supplement 1), 67.

Ebbeling, C., Pawlak, D. \& Ludwig, D. (2002). Childhood Obesity: Public Health Crises, Common Sense Cure. Lancet, 360, 473-482.

Faculdade de Ciências da Nutrição e Alimentação da Universidade do Porto \& Instituto do Consumidor (2004). GuiaOs Alimentos na Roda. Lisboa: Instituto do Consumidor.

Faculdade de Ciências da Nutrição e Alimentação da Universidade do Porto \& Instituto do Consumidor. (2009). A Nova Roda dos Alimentos... um guia para a escolha alimentar diária! Lisboa: Instituto do Consumidor.

Franchini, B., Rodrigues, S., Graça, P., \& Almeida, M.D.V. (2004). A nova Roda dos Alimentos... um guia para a escolha alimentar diária! Nutrícias, 4, 55-56.

Fisberg, M. (2005). Actualização em obesidade na infância e adolescência. São Paulo: Atheneu.

Garcia, R., \& Canesqui, A. (Org.) (2005). Antropologia e Nutrição: Um Diálogo Possível. Rio de Janeiro: Editora Fiocruz.

Harris, J.L., Pomeranz, J.L., Lobstein, T. \& Brownell, K.D. (2009). A crisis in the marketplace: how food marketing contributes to childhood obesity and what can be done. Annual Review of Public Health, 30, 211-225.

Livingstone, S. (2005). Assessing the research base for the policy debate over the effects of food advertising to children. International Journal of Advertising, 24, 273-296.

Michaela, J. \& Contento, I. (1986). Cognitive, Motivational, Social, and Environmental Influences on Children's Food Choices. Health Psychology, 29(3), 128-213.

Peres, E. (1994). Saber comer para melhor viver. Lisboa: Caminho.

Reichembach, M. (2004). A Refeição em Família: Um Lugar de Encontro Entre a História da Alimentação e da Enfermagem. Cogitare Enfermagem, 9(2), 53-65.

Rossi, C., \& Silveira, T. (2002). Pesquisa sobre Culturas Nacionais. O Inexorável Futuro do Marketing na Globalização. Revista Interdisciplinar de Marketing, 1(2), 6-22.

Savage, J., \& Fisher, J. \& Birch, L. (2007). Parental Influence on Eating Behavior: Conception to Adolescence. The Journal of Law, Medicine \& Ethics, 35(1), 22-34.

Serra, G., \& Santos, E. (2003). Saúde e Media na Construção da Obesidade e do Corpo Perfeito. Ciência Saúde Colectiva, 8(3), 691-701.

Story, M. \& French, S. (2004). Food advertising and marketing directed at children and adolescents in the US. International Journal of Behavioral Nutrition and Physical Activity, 1. Available at http://www.ijbnpa.org/content/pdf/1479-5868-1-3.pdf. Accessed January 10, 2016.

Strachan, J. \& Pavie-Latour, V. (2008) Food for thought: shouldn't we actually target food advertising more towards kids and not less? International Journal of Market Research, 50, 13-27.

von Normann, K. (2009). The impact of lifestyles and food knowledge on the food patterns of German children. International Journal of Consumer Studies, 33, 382-391.

Westenhoefer, J. (2002). Establishing Dietary Habits during Childhood for Long-Term Weight Control. Annals of Nutrition and Metabolism, 46 (suppl 1), 18-23.

World Health Organization (WHO) (2003). Diet, Nutrition and the Prevention of Chronic Diseases. Genève: Technical Report Series 916. 